\title{
Anti-collagen type v: a marker of early systemic sclerosis?
}

\author{
Michelle R Ugolini-Lopes ${ }^{*}$ (D, Elenice Mantovani, Virgínia Lucia N Bonoldi, Ana Cristina de Medeiros Ribeiro, \\ Eloisa Bonfá, Natalino Yoshinari and Danieli Andrade
}

\begin{abstract}
Objective: To evaluate the frequency of anti-collagen type $V$ in humans with early systemic sclerosis (SSc) compared to defined SSC patients and healthy controls, since collagen type $V$ was shown to be overexpressed in early SSC patients' skin and there is no data concerning the presence of this antibody in early stages of human SSC. Experimental studies showed that animal models immunized with collagen type $V$ developed a disease similar to human systemic sclerosis (SSc), with antibodies production, mainly in early stages post-immunization.

Methods: Eighty-one female SSc patients were included and divided into two groups: early-SSC (18 patients-EULAR Preliminary Criteria) and defined-SSC (63 patients-ACR Criteria 1980). The control group consisted of 19 healthy women age-matched to Early-SSc group. Anti-collagen type $\vee$ was performed by ELISA. Data was analyzed by appropriate tests.

Results: The prevalence of anti-collagen type $\mathrm{V}$ in early-SSC, defined-SSC and control groups was respectively 33, 17 and $5 \%(p=0.07)$. SSc patients with anti-collagen type $\mathrm{V}$ had shorter disease duration compared to those without this antibody (8.8 \pm 5.1 vs. $14.7 \pm 8.9, p=0.006)$. Likewise, early-SSc patients with anti-collagen $V$ also had a shorter disease duration than patients negative for this antibody ( $4.6 \pm 2.2$ vs. $9.7 \pm 5.2, p=0.04)$. No association with clinical subsets or scleroderma antibodies specificities was observed $(p>0.05)$.

Conclusion: The production of anti-collagen type V in SSC seems to be an early event independent of other antibodies specificities. Further studies are necessary to determine if the underlying mechanism for this chronology involves a primary immune response to abnormal expression of collagen type $\mathrm{V}$.
\end{abstract}

Keywords: Collagen type V, Systemic sclerosis, Scleroderma, Antibodies, Biomarker, Diagnostic test

\section{Introduction}

Collagen type $\mathrm{V}$ is a highly immunogenic extracellular matrix protein with preserved globular and telopeptide domains found inside heterotypic fibrils mixed with collagen types I and III [1]. In humans, it is detected in many tissues including skin, lungs, gastrointestinal tract, cornea, liver, spleen and vessels basement membrane [1].

The literature supports evidence that abnormal expression of collagen type $\mathrm{V}$ might trigger several pathogenic events including autoimmunity [2-5], fibrosis $[2,5-7]$ and vasculopathy [8]. Interestingly, these events also represent the main triad of Systemic Sclerosis (SSc) pathogenesis. In scleroderma patients, a positive correlation between

\footnotetext{
* Correspondence: michelleugolini@gmail.com

Rheumatology Division, Hospital da Clinicas HCFMUSP, Faculdade de Medicina, Universidade de Sao Paulo, São Paulo, SP, Brazil
}

collagen V expression and Modified Rodnan Skin Score was reported with increased collagen $\mathrm{V}$ alpha-1 and alpha-2 mRNA expression levels [7].

Rabbits immunization with human type V collagen induces a disease similar to human SSc, with autoimmunity, vasculopathy and tissue fibrosis [6,9]. Of note, the anti-collagen type $\mathrm{V}$ antibody production had an early peak at 30 days [4]. Histological analysis revealed extracellular matrix remodeling with fibrosis and vasculitis in these animals [4].

Further demonstration that morphological changes in rabbit skin have a distinct characteristic along the immunization process reinforces that tissue damage is dynamic and sequential. In fact, biopsies performed on days 7, 15 and 30 in animals submitted to immunization with collagen type $\mathrm{V}$ revealed that right after immunization, the

(C) The Author(s). 2019 Open Access This article is distributed under the terms of the Creative Commons Attribution 4.0 International License (http://creativecommons.org/licenses/by/4.0/), which permits unrestricted use, distribution, and 
endothelial basement membrane was disrupted [10]. Given that early lesions may have a key role in the underlying pathogenic process, authors speculated that epitopes of collagen type $\mathrm{V}$ were expressed as new antigens leading to the production of high titers of anti-collagen type $V$ [7]. Supporting this notion, type $\mathrm{V}$ collagen is overexpressed in the skin of human patients with early stages of SSc when compared to late-stage [7].

Concerning autoantibodies in human scleroderma, anti-topoisomerase I (anti-Scl70) and anticentromere antibodies are a hallmark of this disease related to distinct clinical manifestations [11]. Antibodies that react with collagen $\mathrm{V}$ epitopes expressed on native as well as with heat-denatured collagen $\mathrm{V}$ molecule were also reported in one-third of overall SSc sera [3]. There are, however, no data concerning the presence of this antibody in early systemic sclerosis.

Our aim was therefore to compare the frequency of anti-collagen type $\mathrm{V}$ antibodies in human subsets of early and defined SSc. We also evaluated the possible association of anti-collagen type $\mathrm{V}$ antibodies with scleroderma specific antibodies.

\section{Patients and methods}

\section{Study design}

This is an observational study with cross-sectional design developed at an outpatient clinic of a tertiary hospital between 2012 and 2014. The final study population consisted of 81 female SSc patients of the Rheumatology Division of our Institution, who were divided in the following groups: 18 early-SSc patients (according to EULAR Very Early SSc Preliminary Criteria [12]) and 63 non-early SSc patients, that we called defined-SSc group [diffuse $(n=27)$ and limited SSc $(n=36)$ according to ACR Criteria 1980 [13]]. Nineteen healthy female individuals age-matched to the early-SSc group comprised the control group.

The inclusion criteria for the study were females, 18 years of age or older, with established disease: Very Early Systemic Sclerosis (EULAR Preliminary Criteria [12]) or Systemic Sclerosis (ACR Criteria 1980 [13]). The exclusion criteria for the study were refusal to participate $[n=1]$, males $[n=3]$, inconclusive criteria for the diagnosis $[n=3]$, overlapping syndromes and other collagen diseases $[n=2]$. Patients were evaluated in the outpatient Rheumatology Clinic, assessed for inclusion and exclusion criteria. For the control group the same inclusion and exclusion criteria were established, except for the definition of the disease. All patients and controls included in the study agreed and signed the informed consent. This study was approved by the Institution's local ethics committee (CEP \# 30955713.0.0000.0068).

SSc patients were divided in two groups: early-SSc group and defined-SSc group. The early-SSc group was defined by the presence of objective Raynaud's phenomena, puffy fingers and positive antinuclear antibodies (ANA) associated with either a scleroderma pattern on capillaroscopy and/or specific SSc antibodies [12]. The defined-SSc group was composed of patients with established disease, with diffuse $(n=27)$ or limited $(n=36)$ form of Systemic Sclerosis (ACR Criteria 1980 [13]).

All medical records were obtained on an ongoing electronic database established in 2000 containing the relevant parameters for this study. The disease duration was defined as the first non-Raynaud's phenomena clinical feature until now. ANA, specific SSc antibodies (anti-centromere and anti-Scl70) and anti-collagen $\mathrm{V}$ antibodies were tested in blood samples collected at entry. Capillaroscopy and imaging tests such as echocardiography, lung tomography, barium swallow and endoscopy were obtained from routine evaluation during the study within 1 year of study entry.

After signing the informed consent, the patients underwent a complete clinical evaluation with Modified Rodnan Score [14], and blood samples were collected. All patient's serum remained stored at $-70{ }^{\circ} \mathrm{C}$ until tested for autoantibody analysis.

\section{Detection of Anti-collagen type $\mathbf{V}$}

Anti-Collagen type V was performed by ELISA. Briefly, wells of polystyrene microplates (Immulon $1 \mathrm{~B}$ plaque) were sensitized overnight with $200 \mu \mathrm{L}$ of purified human collagen V (Sigma) $(1 \mathrm{~g} / \mathrm{ml})$ and then blocked with BSA $1 \%$ (Sigma) for $1 \mathrm{~h}$ and 30 min inside a humid chamber at room temperature. The diluted 1:50 serum samples were added to the wells and tested in duplicates. The conjugate used was the anti-human IgG Sigma (A8542) at $1 / 1000$ dilution. The reaction was revealed after adding a solution of disodium phosphate $20 \mathrm{mg}$ Sigma P-nitrophenylphosphate (N2765) in $20 \mathrm{~mL}$ of glycine buffer. The optical density (OD) was read at $405 \eta \mathrm{m}$ (ELISA Multiskan MS, Labsystems, Helsinki, Finland). Positive results were defined as $\mathrm{OD}=3 \mathrm{SD}$ above the mean OD of controls sera samples.

\section{Detection of antinuclear antibodies}

Antinuclear antibodies were detected by indirect immunofluorescence using HEp-2 cells as substrate following the recommendations of the 3rd Brazilian Consensus for research autoantibodies in Hep-2 cells (ANA) [14].

\section{Detection of anti-Scl70}

Anti-Scl70 was detected by ELISA. Serum samples at 1:100 dilution were added to the wells of commercially available plates containing immobilized Scl70 antigen (ELISA Hemagen Diagnostics Inc., Columbia, NY). The optical density (OD) was read at $405 \mathrm{~g}$ (ELISA Multiskan MS, Labsystems). 
Table 1 Comparison of demographic data and frequency of autoantibodies in early-SSc, defined-SSc and control groups

\begin{tabular}{|c|c|c|c|c|}
\hline & $\begin{array}{l}\text { Early-SSC } \\
N=18\end{array}$ & $\begin{array}{l}\text { Defined-SSC } \\
N=63\end{array}$ & $\begin{array}{l}\text { Control } \\
N=19\end{array}$ & $p$ \\
\hline Mean age, years (SD) & $45.2( \pm 16.2)$ & $56.0( \pm 15.1)$ & $44.9( \pm 16.9)$ & 0.004 \\
\hline Disease duration, years (SD) & $8.0( \pm 5.0)$ & $15.1( \pm 8.8)$ & - & $<0.001$ \\
\hline Anti-collagen type $\mathrm{V}, \mathrm{n}(\%)$ & $6(33 \%)$ & $10(16 \%)$ & $1(5 \%)$ & 0.07 \\
\hline ANA, n (\%) & $18(100 \%)$ & $62(98 \%)$ & - & 0.90 \\
\hline Anti-Scl70, n (\%) & $3(17 \%)$ & $19(30 \%)$ & - & 0.68 \\
\hline Anticentromere, n (\%) & $9(50 \%)$ & $17(27 \%)$ & - & 0.24 \\
\hline
\end{tabular}

Values are expressed in $\mathrm{n}$ : number and percentage (\%), or average \pm standard deviation (SD). ANA Antinuclear antibodies, Anti-SCI70 anti-topoisomerase I

\section{Statistical analysis}

The three groups were compared concerning the positivity of anti-collagen type V. Clinical and laboratorial features were also compared between groups searching for selection bias. The quantitative results were expressed as mean \pm standard deviation (SD). The assessment of normal distribution data was performed with the Kolmogorov-Smirnov test. Categorical variables were compared between groups using Fisher test or Chi-square test when appropriate. Continuous variables were compared between groups using T-Student test, Mann Whitney or ANOVA when appropriate. The tests were conducted with a significance level of $5 \%$.

\section{Results}

The three groups had significant differences regarding mean age $(p=0.004)$. Early-SSc patients were younger than those in the defined-SSc group (45.2 vs. 55.6 years, $p=0.001)$, and their mean age was comparable to the controls (45.2 vs. 44.9 years, $p=0.90)$. Early-SSc group also had a shorter mean disease duration compared to defined-SSc group $[8.0( \pm 5.0)$ vs. $15.1( \pm 8.8)$ years, $p<0.001$ ] (Table 1 ).

Concerning autoantibodies profile, a trend to a higher frequency of anti-collagen type $\mathrm{V}$ was observed in early-SSc and defined-SSc groups compared to the control group $(p=0.07)$, with a significant difference solely for the comparison between early-SSc and controls (33\% vs. $5 \%, p=0.04)$. ANA was uniformly positive, except for one patient, and frequencies of anti-Scl70 $(p=0.68)$ and anti-centromere $(p=0.24)$ were similar in early-SSc and defined-SSc groups (Table 1).

Comparison of all SSc patients with and without anti-collagen type $\mathrm{V}$ antibodies revealed that patients positive for this antibody had a shorter disease duration $(8.8+5.1$ vs. $14.7+8.9$ years, $p<0.006)$. Frequencies of ANA and SSc specific antibodies were alike in patients with and without this antibody $(p>0.05)$. Similarly, no difference between these groups was observed in the frequencies of lung and esophageal involvement or in the mean Rodnan score. (Table 2).

Further evaluation of Early-SSc group with and without anti-collagen type $\mathrm{V}$ demonstrated that positivity for this antibody was associated with younger mean age $(29.5 \pm 11.2$ vs. $53.0 \pm 12.1, p=0.001)$ and shorter disease duration $(4.6 \pm 2.2$ vs. $9.7 \pm 5.2$ years, $p=0.04)$. The frequency of anti-collagen type $\mathrm{V}$ was also higher in patients with disease duration less than 5 years $(83 \%$ vs. $8 \%, p=0.03$ ). (Table 3).

\section{Discussion}

Our results showed that the prevalence of anti-collagen type $\mathrm{V}$ seems to be increased in patients with early systemic sclerosis, and is not dependent on other antibodies specificities.

Table 2 Comparison of demographic, clinical and laboratorial data of SSC patients with and without anti-collagen V

\begin{tabular}{llll}
\hline & Positive Anti-collagen $V$ & Negative Anti-collagen $V$ & $N=65$ \\
\hline Disease duration, years (SD) & $N=16$ & $14.7 \pm( \pm .9)$ & $12 / 65(18 \%)$ \\
Early-SSc, $\mathrm{n}(\%)$ & $8.8( \pm 5.1)$ & $10.5( \pm 12.0)$ & 0.006 \\
Rodnan Score, $\mathrm{n}(\mathrm{SD})$ & $6 / 16(38 \%)$ & $43 / 65(66 \%)$ & 0.17 \\
Interstitial lung disease, $\mathrm{n}(\%)$ & $10.9( \pm 12.1)$ & $13 / 65(20 \%)$ & 0.82 \\
Pulmonary hypertension, $\mathrm{n}(\%)$ & $6 / 16(38 \%)$ & $42 / 65(65 \%)$ & 0.20 \\
Esophageal disease, $\mathrm{n}(\%)$ & $3 / 16(19 \%)$ & $64 / 65(98 \%)$ & 0.70 \\
ANA, $\mathrm{n}(\%)$ & $8 / 16(50 \%)$ & $17 / 65(26 \%)$ & 0.80 \\
Anti-Scl 70, $\mathrm{n}(\%)$ & $16 / 16(100 \%)$ & $23 / 65(35 \%)$ & 0.60 \\
Anticentromere, $\mathrm{n}(\%)$ & $5 / 16(31 \%)$ & 0.68 \\
\hline
\end{tabular}

Values are expressed in $\mathrm{n}$ : numbers and percentage (\%), or average \pm standard deviation (SD). ANA Antinuclear antibodies, Anti-SCI70 anti-topoisomerase I 
Table 3 Data comparison of early-SSc patients with and without anti-collagen type $\mathrm{V}$

\begin{tabular}{llll}
\hline & Positive Anti-collagen $V$ & Negative Anti-collagen $V$ & $N=12$ \\
\hline Mean Age, years (SD) & $N=6$ & $53.0( \pm 12.1)$ & 0.001 \\
Disease duration, years (SD) & $29.5( \pm 11.2)$ & $9.7( \pm 5.2)$ & 0.04 \\
Disease duration $\leq 5$ years, $\mathrm{n}(\%)$ & $4.6( \pm 2.2)$ & $1(8 \%)$ & 0.03 \\
\hline
\end{tabular}

Values are expressed in $n=$ number and percentage (\%), or average \pm standard deviation (SD)

This is the first study measuring anti-collagen type $\mathrm{V}$ in patients with early SSc. The previous work assessing anti-collagen antibodies evaluated several types of anti-collagen antibodies (I, II, III, IV and V) in 35 SSc patients, but the authors did not clarify any disease subsets or disease duration [3]. The overexpression of collagen type $\mathrm{V}$ in the skin of patients in early stages of SSc was reported, but this autoantibody was not assayed in the patients' sera [6]. We studied a homogeneous population (only women over 18 years), and excluded all overlapping immune diseases to minimize confounding factors.

The frequency of anti-collagen type V in early SSc patients was higher than in controls, and the only previous study evaluating this antibody specificity in the overall group of SSc had a small size that did not allow for a statistical analysis [3]. The discrimination of SSc subsets in the present study was relevant, since this association was not observed in the defined group, which suggests that this antibody production is an early event in the disease, as it was also reported in animal models [4]. Supporting this notion, early SSc patients with anti-collagen type $\mathrm{V}$ had shorter disease duration than those without these antibodies.

Anti-collagen type $\mathrm{V}$ did not associate with anti-topoisomerase I, or with anticentromere antibodies, suggesting an independent chronologic antibody production in human SSc. Reinforcing this discrepancy, unlike the other specific SSc antibodies, anti-collagen type $\mathrm{V}$ did not associate with any particular clinical manifestation of the disease.

Although this is the largest study in the literature assessing anti-collagen type $\mathrm{V}$ in SSc, it is important to highlight that our early-SSc sample was limited and that a larger cohort is needed to validate our findings. From our standpoint, the inclusion of patients with less than 3 years of disease could emphasize the role of anti-collagen type $\mathrm{V}$ during earlier stages of the disease.

\section{Conclusions}

The production of anti-collagen type $\mathrm{V}$ in SSc seems to be an early event that is not dependent on other antibodies specificities. Further studies are necessary to determine if the underlying mechanism for this distinct chronology involves a primary immune response to an abnormal expression of collagen type $\mathrm{V}$, similar to that observed in an experimental model [9].
Abbreviations

ACR: American College of Rheumatology; ANA: Antinuclear antibodies; EULAR: European League Against Rheumatism; SSc: Systemic sclerosis

\section{Acknowledgements}

Not applicable.

Funding

Not applicable.

\section{Availability of data and materials}

The datasets used and/or analysed during the current study are available from the corresponding author on reasonable request.

\section{Authors' contributions}

MRUL made substantial contributions to the conception and design, acquisition of data, methodology, investigation, analysis and interpretation of data, and to the writing of the original draft of this manuscript; EM has been involved in the formal analysis of the study and its methodology; VLNB has also been involved in the formal analysis of the study and its methodology; ACMR was also been responsible for the formal analysis, methodology, in addition to writing review and editing of the manuscript; EB contributed with the conceptualization and supervision of the research, writing review and editing of the manuscript; NY involved himself with project conceptualization, and with the review and approval of the manuscript; DCOA was involved with conceptualization, project administration, supervision, and also with the writing review and editing of the manuscript. All the above authors read and approved the final manuscript.

\section{Ethics approval and consent to participate}

This study was approved by the Institution's local ethics committee (Comitê de Ética em Pesquisa do Hospital das Clínicas da Universidade de São Paulo - CEP \# 30955713.0.0000.0068).

\section{Consent for publication \\ Not applicable.}

\section{Competing interests}

The authors declare that they have no competing interests.

\section{Publisher's Note}

Springer Nature remains neutral with regard to jurisdictional claims in published maps and institutional affiliations.

Received: 20 August 2018 Accepted: 1 May 2019

Published online: 14 May 2019

\section{References}

1. Fessler JH, Fessler LI. Type V collagen. In: Mayne R, Burgeson R, editors. Biology of extracellular matrix: structure and function of collagen types. London: Academic; 1987. p. 81-97.

2. Burlingham WJ, Love RB, Jankowska-Gan E, Haynes LD, Xu Q, Bobadilla JL, et al. IL-17-dependent cellular immunity to collagen type $V$ predisposes to obliterative bronchiolitis in human lung transplants. J Clin Invest. 2007; 117(11):3498-506.

3. Riente L, Marchini B, Dolcher MP, Puccetti A, Bombardieri S, Migliorini P. Anti-collagen antibodies in systemic sclerosis and in primary Raynaud's phenomenon. Clin Exp Immunol. 1995;102:354-9. 
4. Callado MRM, Viana VST, Vendramini MBG, Leon EP, Bueno C, Velosa APP, et al. Autoantibody profile in the experimental model of scleroderma induced by type $V$ human collagen. Immunology. 2007;122(1):38-46.

5. Tiriveedhi V, Angaswamy N, Brand D, Weber J, Gelman AG, Hachem R, et al. A shift in the collagen $V$ antigenic epitope leads to $T$ helper phenotype switch and immune response to self-antigen leading to chronic lung allograft rejection. Clin Exp Immunol. 2012;167(1):158-68.

6. Bezerra MC, Teodoro WR, Oliveira CC, Velosa APP, Ogido LT, Galditano G, et al. Scleroderma like remodelling induced by type $\mathrm{V}$ collagen. Arch Dermatol Res. 2006;298(2):51-7.

7. Martin P, Teodoro WR, Velosa AP, de Morais J, Carrasco S, Christmann RB, et al. Abnormal collagen $V$ deposition in dermis correlates with skin thickening and disease activity in systemic sclerosis. Autoimmun Rev. 2012;11(11):82735.

8. Dart ML, Jankowska-Gan E, Huang G, Roenneburg DA, Keller MR, Torrealba $J R$, et al. Interleukin-17-dependent autoimmunity to collagen type $V$ in atherosclerosis. Circ Res. 2010;107(9):1106-16.

9. Teodoro WR, Velosa AP, Witzel SS, Garippo AL, Farhat C, Parra ER, Sonohara S, Capelozzi VL, Yoshinari NH. Architectural remodelling in lungs of rabbits induced by type $V$ collagen immunization: a preliminary morphologic model to study diffuse connective tissue diseases. Pathol Res Pract. 2004; 200(10):681-91.

10. de Oliveira CC, Velosa AP, Parra ER, Capelozzi VL, Teodoro WR, Yoshinari NH. Histomorphometric analysis of cutaneous remodeling in the early stage of the scleroderma model. Clinics (Sao Paulo). 2009;64(6):577-83.

11. Avouac J, Fransen J, Walker UA, Riccieri V, Smith V, Muller C, et al. EUSTAR group. Preliminary criteria for the very early diagnosis of systemic sclerosis: results of a Delphi consensus study from EULAR scleroderma trials and research group. Ann Rheum Dis. 2011;70(3):476-81.

12. Masi AT. And subcommittee for scleroderma criteria of the American rheumatism association diagnostic and therapeutic criteria committee (1980) preliminary criteria for the classification of systemic sclerosis (scleroderma). Arthritis Rheum. 1980;23(5):581-90.

13. Furst DE, Clements PJ, Steen VD, Medsger TA Jr, Masi AT, D'Angelo WA, et al. The modified Rodnan skin score is an accurate reflection of skin biopsy thickness in systemic sclerosis. J Rheumatol. 1998;25(1):84-8.

14. Dellavance A, Gabriel A Jr, Nuccitelli B, Taliberti BH, von Mühlen CA, Bichara CDA, et al. III Brazilian consensus for research autoantibodies in Hep-2 cells (ANA). Recommendations for standardization of test autoantibodies screening in HEp-2 cells, quality control and clinical associations. Rev Bras Reumatol. 2009:49(2):89-109.

Ready to submit your research? Choose BMC and benefit from:

- fast, convenient online submission

- thorough peer review by experienced researchers in your field

- rapid publication on acceptance

- support for research data, including large and complex data types

- gold Open Access which fosters wider collaboration and increased citations

- maximum visibility for your research: over $100 \mathrm{M}$ website views per year

At $\mathrm{BMC}$, research is always in progress.

Learn more biomedcentral.com/submissions 